of alkanes on graphitet. So on graphite the double-row structure is energetically favourable, allowing the alkyls to be separated by $3 a_{0}=4.26 \AA$ and the biphenyls by $2 a_{11}=4.92 \AA$. The latter can be accommodated if the biphenyls are somewhat tilted, but some strain remains, as evidenced by the dislocations that occur every fourth molecule in $8 \mathrm{CB}$ and every fifth molecule in $10 \mathrm{CB}^{2.3}$. In contrast, on $\mathrm{MoS}_{2}$ the closest packing of second-nearest-neighbour molecules is $2,3 a_{i 1}=10.94 \AA$. This larger separation can easily be accommodated by the single-row structure, in which a biphenyl group always lies between two alkyl groups. There is no crowding ( $a$ in figure) and no jumps in the rows as in the double-row structure. The single-row is probably the more energetically favourable as the cyano groups show strong dipole behaviour so that packing them close together (as in the double-row) leads to an increase in electrostatic energy.

Why then does not $10 \mathrm{CB}$ also form the single-row structure on $\mathrm{MoS}_{2}$ ? We believe that the answer lies in the symmetry of

\section{Twists and turns}

SIR-Despite progress in elucidating the structure of ATPases that actively transport cations across cell membranes, the mechanism of this transport remains unknown. In the case of the calcium ATPase from the sarcoplasmic reticulum, the calcium-binding ability of the molecule has been suggested to occur mainly in the carboxy-terminal end ${ }^{1.2}$. Clarke et al.' suggested that the aminoacid residues critical for calcium transport are inside the membrane, based on a prediction that there are ten intramembranous helices in the polypeptide chain of this ATPase. These residues could be clustered to form the calcium-binding site ${ }^{3}$.

But if there are fewer than ten intramembranous helices, the residues involved in translocation would have a different position with respect to the lipid membrane. For $\left(\mathrm{Na}^{+}+\mathrm{K}^{+}\right)$ATPase, for example, a model containing only seven helices has been proposed ${ }^{+}$. Application of this model to the $\mathrm{Ca}^{2+}$ ATPase indicates that residues critical for calcium translocation are all, with one exception, not intramembranous, but located either on the outer or inner aspect of the membrane. Because the hydropathy profile and the release pattern of water-soluble peptide fragments are nearly identical for the carboxy-terminal half of both transport ATPases, it seems unlikely that their structures should differ fundamentally. In the case of the M5-M6 pair of helices, the existence of which is the most controversial, the dilemma is that although there is a long stretch of predominantly hydrophobic residues, this might nevertheless be too short to be accommodated
8CB: both the head and tail are $11.4 \AA$ long, so heads and tails can alternate without leaving vacancies on the substrate. But $10 \mathrm{CB}$ has a $13.7-\AA$-long alkyl group, so a single-row structure would lead to energetically unfavourable vacancies. This argument predicts that other nonsymmetric alkylcyanobiphenyls also will not form the single-row structure. We find that $12 \mathrm{CB}$ on $\mathrm{MoS}_{2}$ does indeed form the double-row structure. We conclude that when molecules containing aliphatic groups wet the surface of layered chalcogenides, the resulting molecular lattice is determined principally by substrate registry, maximizing the number of substrate sites filled by the molecules.

D. P. E. SMITH

W. M. HECKL

IBM Physics Group, Schellingstrasse 4, 8000 München 40, FRG

1. Hara, M. et al. Nature 344, 228-230 (1990).

2. Smith, D.P.E., Hörber, J.K.H., Binnig, G. \& Nejoh, H. Nature 344, 641-644 (1990)

3. Smith, D.P.E., Hörber, H., Gerber, Ch. \& Binnig, G. Science 245, 43-45 (1989)

4. Groscek, A.J. Proc. R. Soc. Lond. A314, 473-498 (1970).

within two intramembranous helices, in accordance with the experimental evidence that part of this region is exposed ${ }^{+}$. Furthermore, experiments with the gastric $\left(\mathrm{H}^{+}+\mathrm{K}^{+}\right)$ATPase have been considered consistent with the location of the loop between M5 and M7 on the extracellular side

These contradictory experimental facts and the proposed folding patterns emphasize the difficulties in deducing membrane protein structure from aminoacid sequence alone. They also highlight the uncertainties about the basic features of ion translocation. If the amino acids essential for $\mathrm{Ca}^{2+}$-dependent phosphorylation are indeed placed on both sides of the membrane, they could form gates that are open only intermittently during calcium-ion translocation. But more experiments are needed to distinguish between the various possibilities.

MARC LE MAIRE

Centre de Génétique Moléculaire,

Laboratoire propre du CNRS,

Associé à I'Université Pierre et Marie Curie (Paris VI)

91198 Gif-sur-Yvette Cedex, France PHILIPPE CHAMPEIL

Service de Biophysique et URA

CNRS 1290,

Département de Biologie,

Centre d'Etudes Nucléaires de Saclay, 91191 Gif-sur-Yvette Cedex, France

Institute of Medical Biochemistry

University of Aarhus, 8000 Aarhus C, Denmark

1. Clarke, D.M. et al. Nature 339, 476-478 (1989)

2. le Maire, M. et al. J. biol. Chem. 265, 1111 (1990)

Green, N.M. Nature 339, 424-425 (1989).

Ovchinnikov, Y A et al. FEBS Lett. 227, 230 (1988)

Sachs. G. et al. J. bioenerg. Biomembr. 21, 573 (1989)

\section{Iron solution}

SIR-Martin et al. (Nature 345, 156-158; 1990 ) in their study of the limitation of phytoplankton growth by iron deficiency conclude by suggesting that exogenous iron may stimulate growth to an extent which may be able to significantly affect the $\mathrm{CO}$-induced greenhouse effect. Davies (Nature 345, 114-115; 1990) indicates that perhaps $10^{6}$ tonnes of iron would be required to carry out this process.

I would like to suggest that an economic, readily available source of this mineral can be found in the manganese/iron concretions or nodules that are widely distributed in considerable quantity on the sea bed in the Pacific and other oceans. Nodules contain approximately $13 \%$ iron, $18 \%$ manganese and other trace elements such as nickel, copper and cobalt in lesser quantities. If they were to be collected and the metal content solubilized and released on site, this could provide an ideal mixture of trace elements for the enhancement of plankton growth.

It is interesting to speculate whether the oceanic depletion of these minerals by their adsorption onto nodules, to some extent regulates $\mathrm{CO}_{2}$ incorporation into ocean biomass, in which case recycling would provide the ideal method for upregulating the whole process.

MARTIN J. VALleR

40 Park St,

Thame, Oxon OX9 3HR, UK

\section{Toxic sludge}

SIR-In 1971 I began a study on the longterm consequences of a heavy application of sewage sludge on extractable levels of a range of trace elements in the soil and on uptake of these elements by herbage. I applied 150 tonnes per hectare of a commercially marketed dried sewage sludge to an unreplicated plot ( 25 square metres) and sowed perennial ryegrass on this area and on an adjacent control plot. I monitored the trace-element composition of soil and herbage in the control and treated plots at 6-monthly intervals for 15 years. (I have published fuller details of the sampling program, analytical methods and earlier results for this trial elsewhere ${ }^{1.2}$.)

The composition of the sludge and of

TABLE 1 TRACE ELEMENTS IN SEWAGE SLUDGE AND IN TREATED AND UNTREATED SOILS

\begin{tabular}{|c|c|c|c|c|c|c|}
\hline Extractant & EDTA & \multicolumn{5}{|c|}{ Total } \\
\hline \multirow[t]{3}{*}{ Sludge } & $\begin{array}{c}\mathrm{Cu} \\
181\end{array}$ & $\begin{array}{c}\mathrm{Pb} \\
710\end{array}$ & $\begin{array}{c}\mathrm{Ni} \\
430\end{array}$ & $\begin{array}{c}\mathrm{Zn} \\
3120\end{array}$ & $\begin{array}{l}\mathrm{Cd} \\
88\end{array}$ & $\begin{array}{l}\mathrm{Hg} \\
23\end{array}$ \\
\hline & \multicolumn{5}{|c|}{ EDTA-extractable } & Tot \\
\hline & $\mathrm{Cu}$ & $\mathrm{Pb}$ & $\mathrm{Ni}$ & $\mathrm{Zn}$ & $\mathrm{Cd}$ & \\
\hline
\end{tabular}

Soil

$\begin{array}{lllllllll}\text { Sept. } 86 & & \text { C } & 3.8 & 14 & 1.6 & 6.8 & 0.27 & 0.88\end{array}$ $\begin{array}{llllll}\mathrm{T} 37 & 51 & 3.5 & 48 & 0.63 & 1.3\end{array}$

C, Untreated soil; $T$, treated. Units in $\mu \mathrm{g}$ per g dry matter. 